\title{
Multidisciplinary study of the "Salinelle" of Paternò mud volcanoes: characteristics of the fluids and possible correlations with the activity of Mt. Etna
}

\author{
Jessica Maria Chicco*,1, Salvatore Giammanco², Giuseppe Mandrone ${ }^{3}$ \\ (1) Dipartimento di Scienze della Terra - Università degli studi di Torino \\ (2) Istituto Nazionale di Geofisica e Vulcanologia, Sezione di Catania, Osservatorio Etneo \\ (3) Dipartimento Interateneo di Scienze, Progetto e Politiche del Territorio (DIST), Università degli studi di Torino
}

Article history: received July 20, 2019; accepted September 30, 2020

\begin{abstract}
Monitoring of hydrothermal fluid emissions can provide detailed information about convective upwelling of geothermal fluids and their geochemical characteristics, as a function of tectonic stress or deeper gas input. In particular, at the Salinelle of Mt. Etna Geosite (Paternò and Belpasso, Eastern Sicily) natural emissions mainly consist of a fluid phase made of salty water, mud, gas and liquid hydrocarbons from an admixture of magmatic and hydrothermal gases. In this framework, our study mainly focused on the thermal and geochemical monitoring of hydrothermal fluids of the most active site, Salinelle dei Cappuccini. N earby hydrothermal vents (Salinelle del Fiume; Salinelle di San Biagio), were also investigated. Analysis of the magnitude and frequency of seismic events all around Mt. Etna were conducted as well. Analysis of daily temperatures showed a constant trend: higher values $\left(>35^{\circ} \mathrm{C}\right.$ ) within the first monitoring period, followed by a strong decrease (down to $9^{\circ} \mathrm{C}$ ), and a new gradual increase over the following months. This trend seems to be linked to magmatic processes occurring at depth below Mt. Etna, and could lead to a modification of the geochemical and thermal characteristics of the fluids issuing at the mud-pools and gas vents of Salinelle. The higher the frequency of seismic events corresponding to higher daily energy released, the higher fluid temperatures observed. Understanding how these fluids blend and what is their relationship with Mt. Etna volcanism can be of great importance in forecasting new eruptive cycles in the case they precede changes in volcanic activity.
\end{abstract}

Key words: Salinelle; Mud volcanoes; Mt. Etna; Geothermal fluids; Hydrothermal fluid emissions.

\section{Introduction}

Forecasting new eruptive cycles at active volcanoes is of extreme importance for civil protection outcomes, but it is still a great challenge, since most of the world's active volcanoes are not ordinarily monitored. Among the most commonly monitored precursory signals are local micro seismicity and ground deformation. In active 


\section{Jessica Maria Chicco et al.}

volcanic regions, elastic-brittle failure of the crust is usually associated with opening of new pathways, which in turn may allow magma ascent [Kilburn, 2018 and references therein]. Formation of new mud volcanoes or variations in the activity of already existing ones have been considered signs of crustal movement associated with both seismic and volcanic events [Davies, 2008; Bonini, 2009, 2012; Manga et al., 2009].

Most mud volcanoes in the world are located in compressional environments, along continental and oceanic convergent plate boundaries such as the Pacific Margin Belt and the Alpine-Tethys Suture Zone [Bonini, 2009; Wan et al., 2019]. Mud volcanoes are generally described as the result of the surface venting of liquefied clay-rich sediments, mixed with salty water and liquid hydrocarbons [Deville and Guerlais, 2009]. Mud volcanism is also associated with relatively shallow hydrocarbon reservoirs formed within sedimentary basins with high sedimentation rates of fine-grained and saturated materials that trap large volumes of organic matter [Pralle and Gudehus, 2003; Castaldi and Coratza, 2017]. In these geological contexts, muddy emissions at the surface derive from overpressure of crustal fluids rich in sediments, salty water, mud and gas [Vanderkluysen et al., 2014]. Alternatively, though less commonly, mud volcanoes can be the result of venting of an abundant pressurized fluid phase without any clay fraction, originated from admixture of magmatic and hydrothermal gases [Giammanco et al., 2016]. Within the latter type of mud volcanoes, the relative proportions of $\mathrm{CH}_{4}, \mathrm{~N}_{2}$, and $\mathrm{CO}_{2}$ in the gas phase can distinguish mud volcanoes and their styles of activity [Baloglanov et al., 2018]. Literature data confirm that some mud volcanoes are not only a simple surface expression of hydrothermal systems linked to nearby magmatic volcanoes, but they can also be hybrid systems, fed both by sedimentary fluids and by deeper fluids [Komatsu et al., 2019].

Until the early $20^{\text {th }}$ century, the causes and sources of mud volcanoes in Italy were generally ascribed to meteorological parameters, but Mercalli in 1883 was the first to envisage a possible link between mud eruptions and seismic events. More recently, Italian mud volcanoes were correlated with compressional tectonics as well as to liquefaction induced by seismic activity [Martinelli and Judd, 2004; Bonini et al., 2009]. In particular, a few hours to a few days after the last strong Italian earthquakes (between 24 August 2016 and 30 October 2016) 17 mud volcanoes erupted in the Marche region (i.e., the closest to the earthquake epicentres), thus strongly suggesting a seismic triggering of mud eruptions [Maestrelli et al., 2017]. On the other hand, Giammanco et al. [2016] showed a possible connection between the mud volcanoes near Mt. Etna, belonging to the "Salinelle of Mt. Etna" Geosite, and the deep magmatic activity of Europe's most active volcano.

The aim of this work was to perform a detailed study of the most peculiar Sicilian mud volcanoes, belonging to the "Salinelle of Mt. Etna" Geosite, located on the lower Southwestern flank of Mt. Etna volcano. In particular, this paper deals with the monitoring of fluids emitted from the "Salinelle" mud volcanoes, as well as with a new assessment of their relationship with Mt. Etna volcanic and seismic activity, since this can be of great importance in forecasting new eruptive cycles of the volcano.

\section{The "Salinelle of Mt. Etna geosite": geographical, geological and geochemical framework}

The "Salinelle of Mt. Etna" Geosite includes three groups of mud volcanoes located a few kilometres from each other on the South-Western flank of Mt. Etna (Figure 1). The local geological features of the three sites are greatly different. The most active and interesting site is called "Salinelle dei Cappuccini" or "Salinelle dello Stadio" and it is located in the western periphery of the town of Paternò on an extinct volcanic hill called "Conetto dei Cappuccini" due to a nearby ancient Capuchins monastery (Figure 2A). The outcropping volcanics are sub-alkali to alkali-sodic lavas belonging to the Piano Provenzana Formation of Ellittico Volcano, a preEtna volcano dated to about $42.1 \pm 10.4$ to $28.7 \pm 12.6$ ka [Branca et al., 2011a, 2011b]. Conversely, the "Salinelle del Fiume" (Figure 2B) are located in a flat area composed of alluvial terraced deposits of the nearby Simeto River, whereas the "Salinelle di San Biagio" or "Salinelle del Vallone Salato" (Figure 2C), extend over an area of several thousand square meters on a substrate of sandy clays dated to Lower Pleistocene [Carveni et al., 2009]. All of the above mud volcanoes are characterized by bland relief, from centimeters to some meters high. During the dry season, the ground surface around the vents is normally covered in a thin crust of white salt (mostly halite) that gives the name to the sites (Salinelle derives from the Italian word for salt: "sale").

The Salinelle mud volcanoes are clearly correlated with regional tectonics [Caracausi et al., 2003a, 2003b]. 
They formed over the accretionary wedge that developed in front of the Apennine-Maghrebian fold and thrust belt, progressively migrating southward over the Pelagian-African foreland [Bonini et al., 2009]. The activity of Salinelle seems linked to seismic events at both a regional and a local scale, the latter because of the magmatic activity of Mt. Etna volcano [Bonfanti et al., 1993; Federico et al., 2019; Napoli et al., 2020]. The fluids emitted from Salinelle are made up of a mixture of gases, mostly $\mathrm{CO}_{2}$ of magmatic origin with a lesser percentage of methane of crustal origin [Caracausi et al., 2003a; Giammanco et al., 1998, 2007; Pecoraino and Giammanco, 2005], and muddy hypersaline water. The latter come from a reservoir confined within the sedimentary rocks of the Etna basement [Carveni et al., 2009; Napoli et al., 2020].

Sometimes, floating oil slicks are also observed [Giammanco et al., 2016]. Waters emitted at the Salinelle dei Cappuccini site are often slightly thermalized, with temperatures reaching about $50^{\circ} \mathrm{C}$ during the strongest mud eruptions. Previous studies made use of chemical geothermometry to estimate an equilibrium temperature of fluids at depth in the range between 120 and $150^{\circ} \mathrm{C}$ [Chiodini et al., 1996]. The presence of $\mathrm{CO}_{2}$ in the bubbling gas in the vents is due to surface emission of deep gas produced from magmatic degassing [Caracausi et al., 2003a; Pecoraino and Giammanco, 2005]. Carbon dioxide is actually one of the first volatile components to be released from magma already at great depth during its ascent towards the surface [Pan et al., 1991; Caracausi et al., 2003a], thus being extremely useful for revealing early stages of magma migration, well before the onset of volcanic eruptions [Bruno et al., 2001; Caltabiano et al., 2004].

Condensation of high-enthalpy fluids of magmatic origin before they reach the surface may explain the emission of the abundant liquid component devoid of a significant clay fraction, as well as the high salinity of waters. Based on the sulfate and chloride content of waters, these fluids would be a result of mixing between steam heated waters and a geothermal brines [Aiuppa et al., 2002, 2004; Liotta et al., 2017]. The above characteristics of the Salinelle revealed their unique features, very different from those of other mud volcanoes of Italy or around the world, whose emissions are typically characterized by clay-rich fluids driven by hydrocarbon-derived methane gas [Bonini et al., 2009].
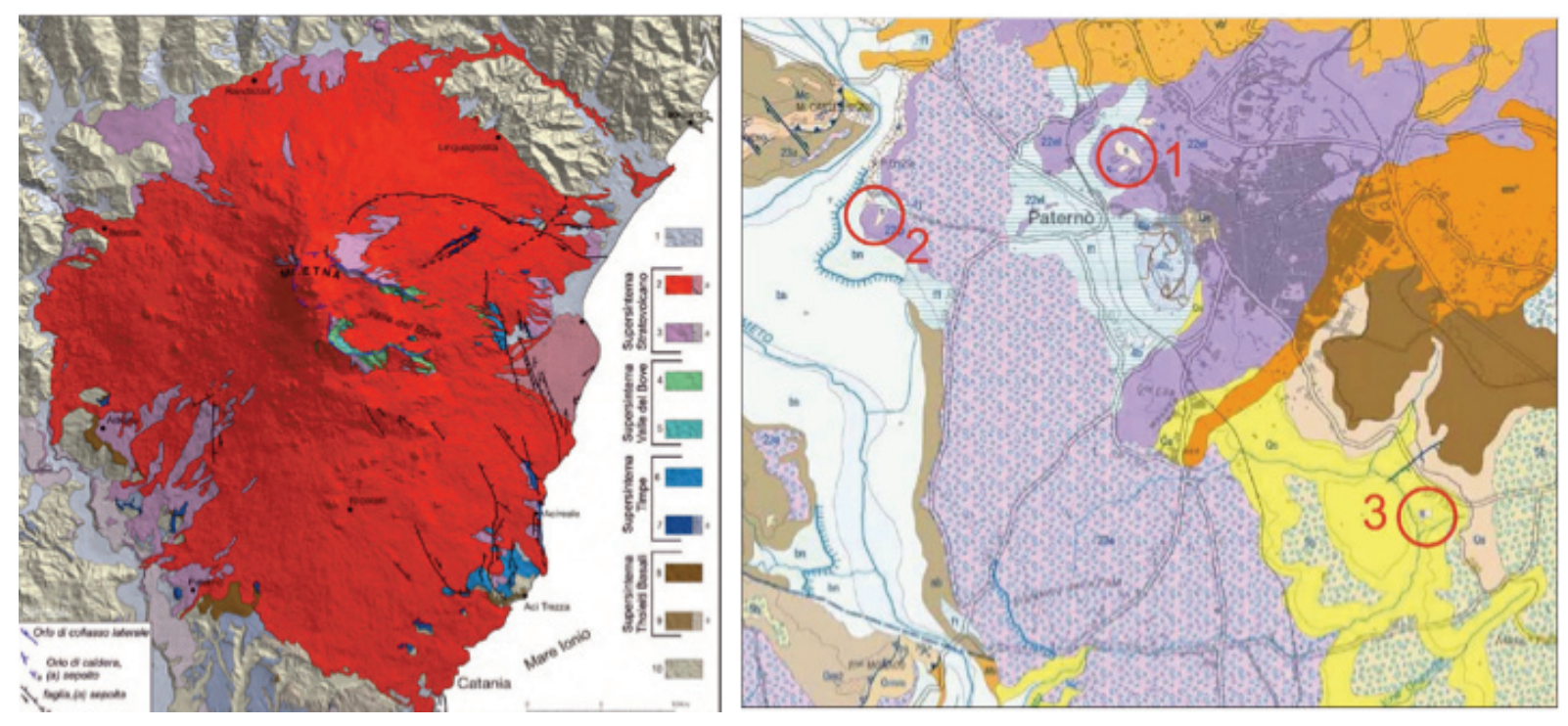

Figure 1. A) Geological sketch map of Mt. Etna, modified from Branca et al. [2015]. The black square in fig. A represents the whole studied area, whose detail is reported in figure B. B) red circles indicate the three investigated sites of the "Salinelle of Mt. Etna” Geosite: 1) "Salinelle dei Cappuccini” or "Salinelle dello Stadio"; 2) "Salinelle del Fiume”; 3) "Salinelle di San Biagio” or "Salinelle del Vallone Salato”. 
Jessica Maria Chicco et al.
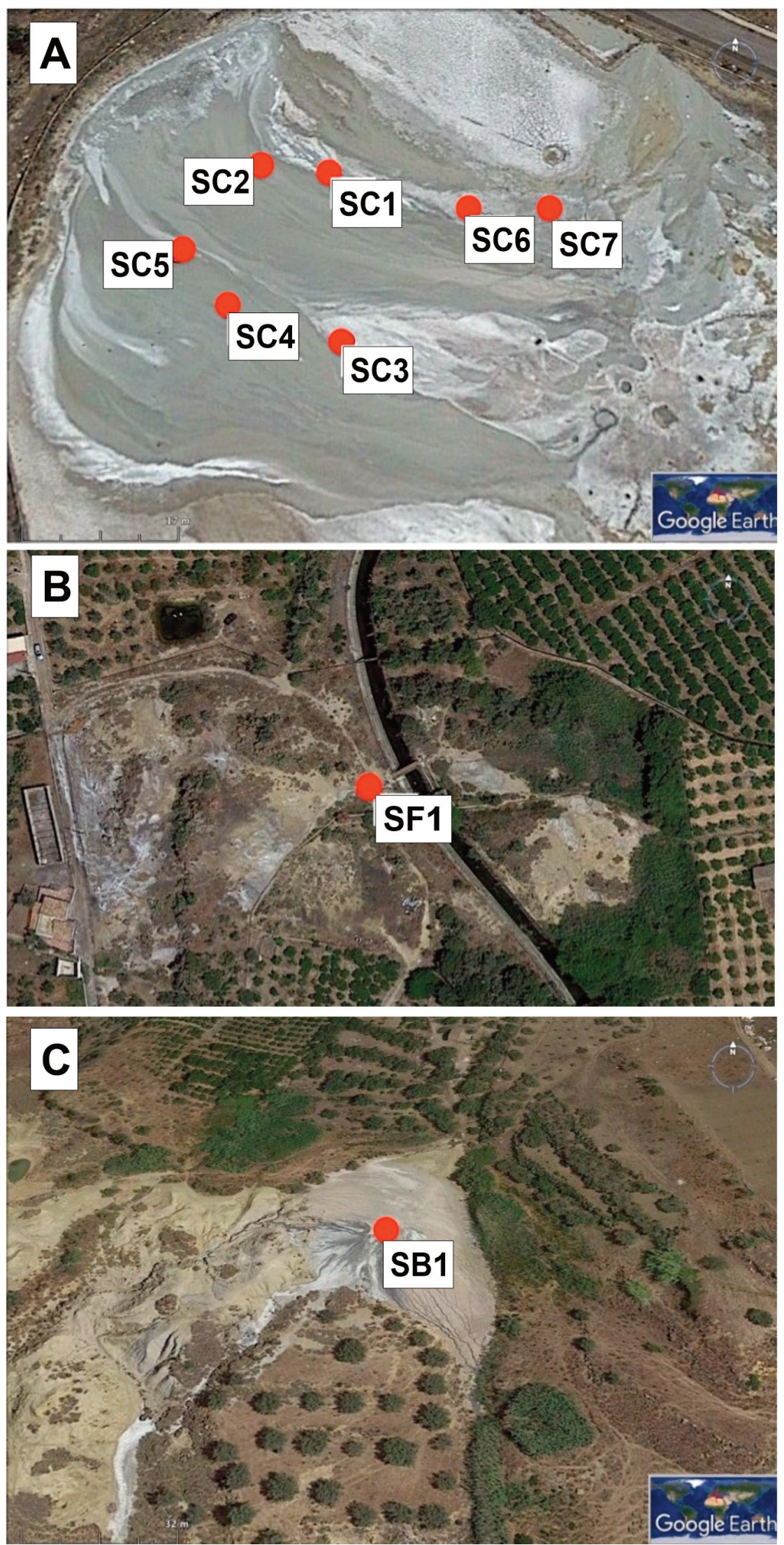

Figure 2. Aerial view of A) Salinelle dei Cappuccini; B) Salinelle del Fiume; and C) Salinelle di San Biagio, showing the main mud vents and mud flows and the location of the monitored sites. The dimensions of the vents vary between a few centimetres and some meters. The whitish areas are those covered in salt (mainly composed of $\mathrm{NaCl}$ ). Images from Google Earth. 


\section{Methods}

Field measurements mainly consisted of thermo-physical and geochemical monitoring of the hydrothermal fluid emissions at selected vents, whereas laboratory analyses consisted of mineralogical determinations of collected samples of the solid materials deposited around the vents. Many vents changed their shape or even location, therefore limiting the choice of suitable vents for a meaningful monitoring of the mud volcanoes activity. Three surveys were carried out at the Salinelle: on May 2018 only at the Salinelle dei Cappuccini, then on November 2018 and on February 2019 at all sites. During the May 2018 survey, four water pools (named SC1 to SC4, Figure 2) were selected based on their visibly stronger gas bubbling and water emission, and higher water temperature. No water samples were collected on that occasion. During November 2018 survey, muddy pools SC3 and SC4, with the addition of the new pool SC5 (see Figure 2), were sampled and analyzed at the Salinelle dei Cappuccini site. We also studied the other two sites within Salinelle (Salinelle del Fiume and Salinelle di San Biagio) and one muddy pool in each site (respectively, SF1 and SB1), where we carried out both field measurements of the main physico-chemical parameters of muddy water and water sampling for laboratory analyses. During the third survey of February 2019, only muddy pools SC3, SC4 and SB1 were sampled and analyzed again, together with two new pools at the Salinelle dei Cappuccini (SC6 and SC7 in Figure 2).

The analyses were coupled with that of the main characteristics of the seismic events in the area of Mt. Etna during the monitored period. For the aims of the present study, we also incorporated both seismological and volcanological data.

\subsection{Thermal properties}

Hypersaline waters emitted from the mud pools at the Salinelle dei Cappuccini were monitored using thermal sensors. Embedded temperature sensors and data loggers (MicroTemp. MadgeTech. Inc.) were directly immersed in the most active and stable water pools (SC3 and SC4 in Figure 3.1), in order to provide continuous, real-time monitoring. The deployed temperature recorders are miniaturized (only $66 \mathrm{~mm}$ tall and 18mm in diameter), selfpowered thanks to small batteries, and have a waterproof stainless steel casing. They can operate in a temperature range from $-40^{\circ} \mathrm{C}$ to $+80^{\circ} \mathrm{C}$ with accuracy of $\pm 0.5^{\circ} \mathrm{C}$. Our recorders were set with a sampling frequency of 15 minutes, in order to store data up to 24 months [Chicco et al., 2018].

Monitoring of water temperature started on May 7, 2018 and ended on April 13, 2019, for a total of 34,675 valid measurements at each site (we discarded initial temperatures due to equilibration of the sensors with water, so as to obtain the same number of measurements at each recorder).

Analyses of the thermal properties of the mud continuously emitted from pools were mainly conducted on the field and consisted on the evaluation of both the thermal conductivity $\lambda\left(\mathrm{W} \mathrm{m}^{-1} \mathrm{~K}^{-1}\right)$ and the temperature of mud. We used a Thermal Property Analyzer (mod. K2DPro, Decagon Devices) that complies the Standards ASTM D5334 and IEE 442 (ASTM 2014; IEE-442 2003). It relies on the Transient Line Source Method (TLS) described in Giordano et al. [2019] and Chicco et al. [2019]. Each of the $\lambda$ and T values represents the average of 5 replicates over 10 sets of measurements. This allowed us to obtain a total of 50 values of temperature and thermal conductivity for each investigated pool.

To better evaluate the thermal behavior of both mud and hypersaline waters of the Salinelle pools, a series of InfraRed (IR) thermal images of the pools were acquired. Field measurements were made both during maximum and minimum daily insulation rates. The device employed was a FLIR E8 thermal camera (FLIR Systems Inc.), designed and calibrated for the Long-Wavelength IR band between 8 and $14 \mathrm{~mm}$. It consists of an uncooled FPA micro bolometer sensor, with IFOV $=2.6 \mathrm{mrad}$ and a resolution of $320 \mathrm{X} 240$ pixel. All thermal images were calibrated with simultaneous real field measurements.

\subsection{Electrical properties and geochemical analysis of fluids}

Electrical conductivity s $(\mu \mathrm{S} / \mathrm{cm}), \mathrm{pH}$ and Electrical Potential $V$ of the hypersaline waters of Salinelle were investigated during field surveys. The deployed equipment was a commercial $\mathrm{pH} /$ Conductivity waterproof handheld meter mod. 340i (WTW Measurement System Inc.) that fulfils the IP67 requirements. 

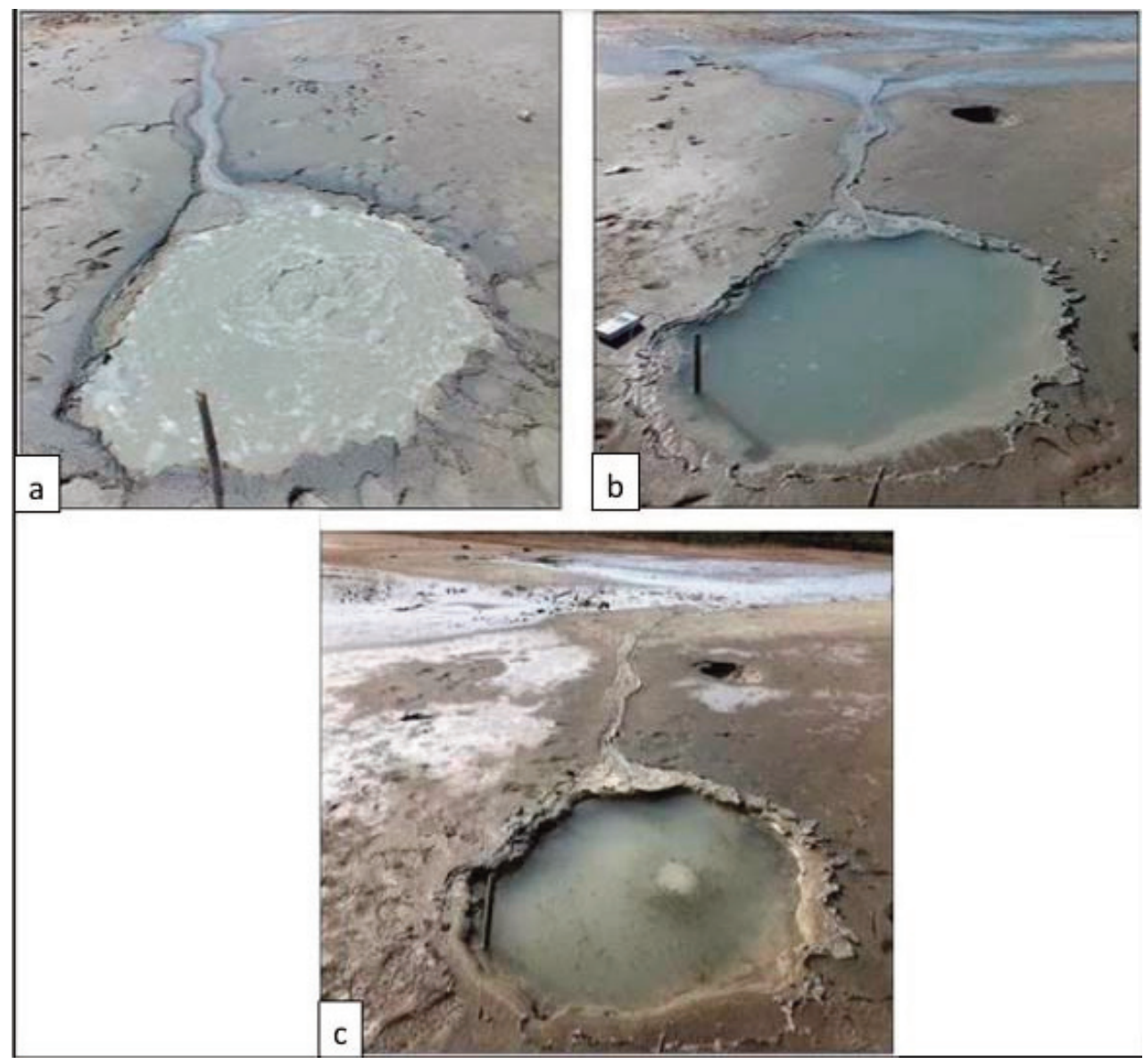

Figure 3. Example of marked changes in shape and size at the same water pool, over three different periods. The example is one of the numerous hydrothermal pools of the "Salinelle dei Cappuccini” site. a) May 2018: Evidence of strong gas bubbling and mud emission, together with some mineral deposits all around the pool; b): November 2018: Only few gas bubble emissions testifying a very weak hydrothermal activity. The pool showed a smaller size, a more rounded shape and increased presence of mineral deposits all around the pool; c): February 2019: Almost complete stop of hydrothermal activity, probably due to shifting of fluids emissions towards other nearby pools.

During the February 2019 field survey only, $\mathrm{CO}_{2}$ determinations were carried out in the bubbling gas phase emitted from some selected bubbling pools of the Salinelle dei Cappuccini. An inverted funnel, connected to the inlet port of a portable battery-powered $\mathrm{CO}_{2}$ meter (CM-0003 model, $\mathrm{CO}_{2}$ meter Inc., combined with a specific software named GasLab®) with a silicon pipe, was placed on single degassing water pools and its rims were kept a few centimeters deep into the water, in order to effectively convey the gas to the detector and thence avoid air contamination in the samples. Before entering the instrument, the gas was pumped through a water trap and a hydrophobic filter, in order to eliminate any trace of water or humidity. No such measurement was possible during the 2018 surveys due to malfunctioning of the $\mathrm{CO}_{2}$ detector. Furthermore, no $\mathrm{CO}_{2}$ measurement was possible at the other two sites of Salinelle because of the much lower degassing activity and the much smaller bubble dimensions.

Samples of muddy water were collected from the most active vents of the three sites during the November 2018 and February 2019 surveys and were later analyzed at the laboratories of the Earth Sciences Department of Torino University, after filtration from the muddy fraction in suspension. The residual liquid phase was first submitted to volumetric analysis, within two days of collection, using automatic titration, in order to evaluate its hydrocarbon $\left(\mathrm{HCO}_{3}^{-}\right)$ions concentration. A 665 Dosimat titrator instrument (Metrohm AG Ltd., Germany) was used for the measurement of bicarbonate ions in the water samples using $\mathrm{HCl} 0.1 \mathrm{~N}$ as titrant solution. Direct ion chromatography was applied for the determination of major and minor cations $\left(\mathrm{Na}^{+}, \mathrm{K}^{+}, \mathrm{Ca}^{2+}, \mathrm{Mg}^{2+}, \mathrm{Li}^{+}\right.$e $\left.\mathrm{NH}_{4}^{+}\right)$and ion chromatography with chemical suppression was applied for determining major anions in solution $\left(\mathrm{Cl}^{-}, \mathrm{Br}^{-}, \mathrm{NO}_{3}{ }^{-}, \mathrm{SO}_{4}{ }^{2-}\right)$, following the procedure of Ershov [2017]. 
The filtered mud suspension was analyzed, too, in order to define its mineralogical composition. Because of the difficulty in detecting the mineral phases with optical techniques, we applied the powder X-Ray Diffraction (XRD) method using the “X’Pert pro” device (Malvern Panalytical@ 2018) set with the Bragg-Brentano geometry [Giordano et al., 2019].

\subsection{Evaluation of seismic parameters}

Seismic events with Magnitude $M \geq 2$ that occurred in the Etna area were collected with a daily frequency by the INGV seismic network during the period of observations. Seismic data were retrieved from http://sismoweb.ct.ingv.it/, whereas volcanological data were retrieved from INGV weekly reports (http://www.ct.ingv.it/en/rapporti/multidisciplinari.html). All local earthquakes were catalogued and plotted and we calculated both the respective daily energies and the cumulated seismic strain release. In particular, the seismic strain release $(\sqrt{E})$ was obtained by cumulative summing of the daily energy (E) of each earthquake (in Ergs), though the use of the Richter [1958] relation:

$$
\log \mathrm{E}=9.99+1.9 \mathrm{M}-0.024 \mathrm{M}^{2}
$$

where M is the earthquake magnitude, following the procedure in Vizzini et al. [2012] and Alparone et al. [2015].

\section{Results and discussion}

\subsection{Physical and chemical characteristics of fluids}

Field surveys at the three Salinelle groups allowed recognition of significant temporal changes both in the style and in the intensity of fluids emissions, with consequent changes in the morphological features of the vents and muddy pools. Even the most stable vents showed some variations in fluid emissions that affected their morphology (Figure 3). However, higher gas or water emissions were not always correlated with higher water temperature values of fluids, as highlighted by InfraRed (IR) thermography measurements (Figure 4).

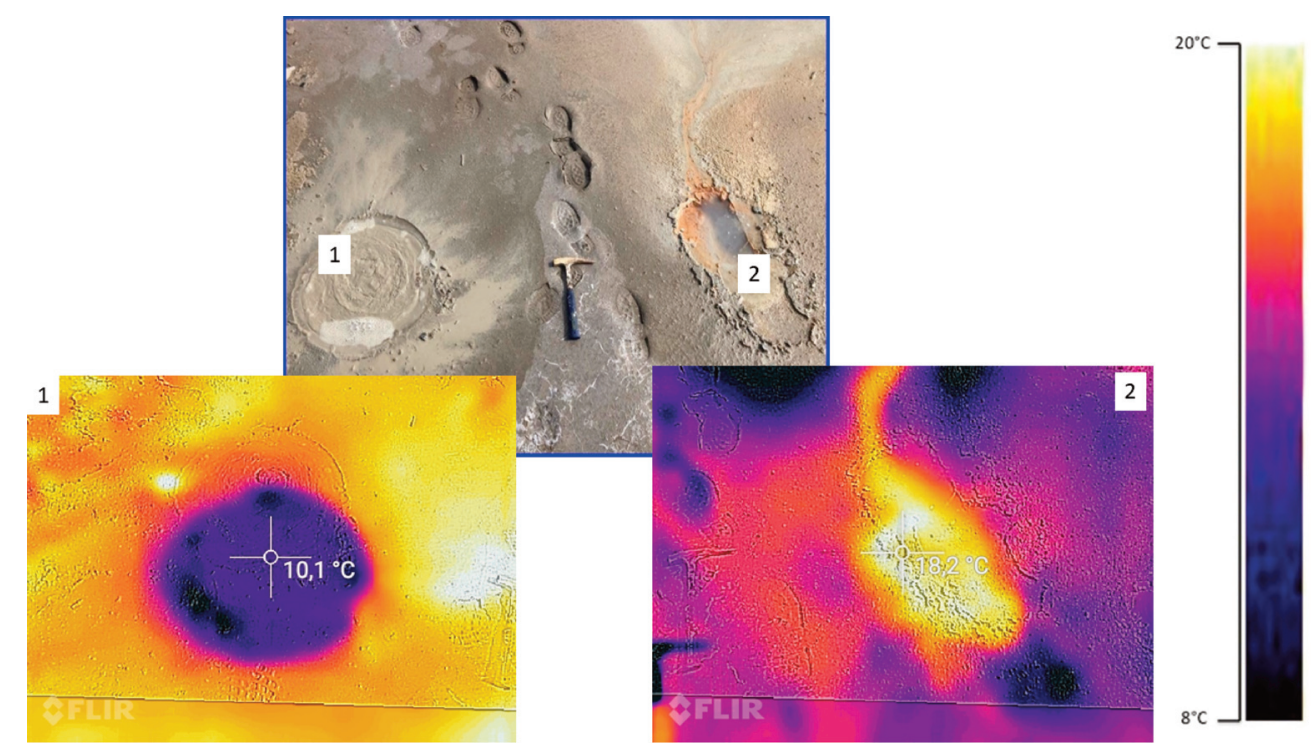

Figure 4. RGB image of two nearby pools at the Salinelle dei Cappuccini, showing a stronger degassing activity (more violent gas bubbling) at pool 1 than at pool 2 of which, thermal images of the same pools are reported. A higher water temperature at pool 2 (lighter colour) than at pool 1 (darker colour), can be observed. Note that pools in the images are not those monitored in this study. 


\section{Jessica Maria Chicco et al.}

Both field measurements and instrumental monitoring of water temperature were mainly focused on the site of Salinelle dei Cappuccini, because water pools there were the hottest. Table 1 and Figure 5 show the measured parameters and the results obtained from the May 2018 survey. Most of the parameters showed relatively comparable values among the sampled pools. All water temperatures were significantly higher than the typical values in Etna's groundwater [e.g., Giammanco et al., 1998; Aiuppa et al., 2004], suggesting a hydrothermal origin of the emitted fluids. The data showed negative correlations between $\mathrm{pH}$ and thermal conductivity $\left(\mathrm{R}^{2}=-0.88\right)$ and between $\mathrm{pH}$ and Eh $\left(R^{2}=-0.96\right)$, whereas a strong positive correlation was consequently observed between Eh and thermal conductivity $\left(\mathrm{R}^{2}=+0.98\right)$.

\begin{tabular}{|c|c|c|c|c|}
\hline \multicolumn{5}{|c|}{ Analytical results of May 2018 field survey } \\
\hline & SC1 & SC2 & SC3 & SC4 \\
\hline $\mathrm{T}\left({ }^{\circ} \mathrm{C}\right)$ & 32.0 & 31.0 & 33.7 & 25.3 \\
\hline pH & 6.5 & 6.4 & 6.0 & 6.2 \\
\hline Cond. $(\mu \mathrm{S} / \mathrm{cm})$ & 110 & 97 & 112 & 92 \\
\hline Eh $(\mathrm{mV})$ & 27 & 29 & 54 & 38 \\
\hline$\lambda\left(\mathrm{W}^{*} \mathrm{~K}^{-1} \mathrm{~m}^{-1}\right)$ & 1.30 & 1.29 & 2.57 & 1.63 \\
\hline
\end{tabular}

Table 1. Physical-chemical parameters (temperature, $\mathrm{pH}$, electrical conductibility, Eh and thermal conductibility $\lambda$ measured in four selected muddy pools of Salinelle dei Cappuccini (SC) during the May 2018 field survey.

Table 2 shows the results of the field and laboratory analyses for the November 2018 samples. Compared with the May 2018 survey, at the Salinelle dei Cappuccini site we observed a general marked decrease in water temperature, electrolytic conductivity and thermal conductivity $(\lambda)$, whereas we measured a slight increase in pH and Eh. The results of the chemical analyses of water confirmed the hyper-salinity of all samples. Major ionic species show that waters have a physical-chemical composition fairly uniform and constant in time for each Salinelle group, with marked prevalence of sodium $\left(\mathrm{Na}^{+}\right)$and chloride $\left(\mathrm{Cl}^{-}\right)$on the other elements.

Analytical results of November 2018 field survey. Ionic concentrations in water are expressed as mg/L.

\begin{tabular}{|c|c|c|c|c|c|}
\hline & SC3 & SC4 & SC5 & SF1 & SB1 \\
\hline $\mathrm{T}\left({ }^{\circ} \mathrm{C}\right)$ & 19.3 & 18.5 & 26.1 & 13.8 & 20.5 \\
\hline pH & 6.7 & 6.4 & 6.2 & 6.6 & 6.6 \\
\hline Cond. $(\mu \mathrm{S} / \mathbf{c m})$ & 49.0 & 63.3 & 105.7 & 59.8 & 50.7 \\
\hline Eh $(\mathrm{mV})$ & 29.5 & 42.0 & 51.0 & 28.0 & 52.0 \\
\hline$\lambda\left(\mathbf{W}^{*} \mathbf{K}^{-1} \mathbf{m}^{-1}\right)$ & 0.89 & 0.80 & 1.37 & 0.88 & 0.90 \\
\hline $\mathrm{Ca}^{++}$ & 1326.8 & 509.4 & 1269.7 & 956.4 & 1027.5 \\
\hline $\mathrm{Mg}^{++}$ & 262.9 & 650.3 & 269.8 & 355.9 & 641.8 \\
\hline $\mathrm{Na}^{+}$ & 21605.1 & 23951.2 & 23097.7 & 27001.4 & 21020.5 \\
\hline $\mathbf{K}^{+}$ & 441.7 & 374.2 & 497.5 & 563.7 & 458.4 \\
\hline $\mathbf{L i}^{+}$ & 265.4 & 258.1 & 265.2 & 271.0 & 257.1 \\
\hline $\mathrm{NH}_{4}^{+}$ & 135.7 & 188.0 & 193.6 & 191.5 & 215.6 \\
\hline $\mathrm{Cl}^{-}$ & 40139.1 & 43760.3 & 43351.4 & 50779.7 & 40077.4 \\
\hline $\mathrm{Br}^{-}$ & 70.7 & 74.9 & 93.4 & 79.7 & 83.5 \\
\hline $\mathrm{NO}_{3}^{-}$ & 7.1 & 0.0 & 55.8 & 0.0 & 315.0 \\
\hline $\mathrm{SO}_{4}^{--}$ & 105.2 & 76.5 & 2152.9 & 99.9 & 44.6 \\
\hline $\mathrm{HCO}_{3}^{-}$ & 266.1 & 466.2 & 427.2 & 725.0 & 275.8 \\
\hline TDS & 64359.8 & 69843.0 & 71247.0 & 80499.2 & 64141.5 \\
\hline
\end{tabular}

Table 2. 
Finally, the analytical results of the February 2019 survey are shown in Table 3.

Analytical results of February 2019 field survey. Ionic concentrations in water are expressed as $\mathrm{mg} / \mathrm{L} . \mathrm{nm}=$ not measured

\begin{tabular}{|c|c|c|c|c|c|}
\hline & SC3 & SC4 & SC6 & SC7 & SB1 \\
\hline $\mathrm{T}\left({ }^{\circ} \mathrm{C}\right)$ & 12.9 & 17.6 & 14.1 & 22.9 & 13.2 \\
\hline pH & 6.4 & 6.5 & 6.6 & 6.3 & 6.7 \\
\hline Cond. $(\mu \mathrm{S} / \mathrm{cm})$ & 69.9 & 80.8 & 81.4 & 58.6 & 38.1 \\
\hline Eh (mV) & 33.0 & 81.0 & 69.0 & 49.0 & 39.0 \\
\hline$\lambda\left(\mathbf{W}^{*} \mathbf{K}^{-1} \mathbf{m}^{-1}\right)$ & 1.39 & 1.51 & 1.40 & 1.43 & 1.11 \\
\hline $\mathbf{C a}^{++}$ & 1178.89 & 1226.7 & 1804.1 & 1551.5 & 2344.6 \\
\hline $\mathrm{Mg}^{++}$ & 331.91 & 737.2 & 290.5 & 291.6 & 789.8 \\
\hline $\mathrm{Na}^{+}$ & 19947.7 & 24205.9 & 24270.7 & 25097.3 & 25677.6 \\
\hline $\mathbf{K}^{+}$ & 419.2 & 368.6 & 509.0 & 597.1 & 436.7 \\
\hline $\mathbf{L i}^{+}$ & 262.5 & 258.4 & 267.7 & 268.9 & 260.1 \\
\hline $\mathrm{NH}_{4}^{+}$ & 158.2 & 189.1 & 174.1 & 201.6 & 211.8 \\
\hline $\mathrm{Cl}^{-}$ & 10302.6 & 46102.7 & 26991.0 & 47997.3 & 50084.1 \\
\hline $\mathrm{Br}^{-}$ & 0.0 & 80.2 & 52.0 & 84.5 & 102.0 \\
\hline $\mathrm{NO}_{3}^{-}$ & 0.0 & 179.0 & 0.0 & 31.8 & 0.0 \\
\hline $\mathrm{SO}_{4}^{--}$ & 56.4 & 304.6 & 564.4 & 53.0 & 0.0 \\
\hline $\mathrm{HCO}_{3}^{-}$ & 688.3 & 1635.0 & 793.3 & 829.9 & 707.9 \\
\hline TDS & 35657.4 & 73652.0 & 54923.3 & 76174.5 & 79839.2 \\
\hline $\mathrm{CO}_{2}(\%)$ & 10.0 & 81.0 & 83.0 & 16.0 & $\mathrm{~nm}$ \\
\hline
\end{tabular}

Table 3.

Comparison among the three surveys showed a general decrease in water temperature at all pools since May 2018 and a general increasing trend of pH values at all sites (Figure 5). However, thermal conductivity at the SC3 and SC4 pools in November 2018 was significantly lower than in the other two surveys. No significant correlation was found between the two studied thermal properties of fluids, namely l and T. Conversely, a strong positive correlation was observed between values of 1 and those of electrolytic conductivity at SC3 and SC4 pools, with $\mathrm{R}^{2}$ values of 0.99 and 0.93 , respectively. This suggests that both the thermal and the electrical properties of the emitted muddy waters depend on the input of deep saline and high-enthalpy fluids, likely brines derived from condensation of vapor-saturated magmatic gases.

We used the chemical composition of the sampled muddy waters to calculate the possible equilibration temperature in the shallow hydrothermal reservoir that feeds the Salinelle mud volcanoes. Assuming a fast ascent of fluids that prevented a significant re-equilibration of the chemical species due to inter-reactions or precipitation of solid phases, we used the triangular Na-K-Mg diagram first proposed by Giggenbach [1988] to obtain a range of equilibration temperatures for partially equilibrated geothermal waters based on the dependence of concentration ratios on temperature. The results (Figure 6) show that all samples plot in the "partially equilibrated waters" area, though very close to the "full equilibrium" curve. Furthermore, they fall within a rather narrow range of temperature values, between 100 and $140^{\circ} \mathrm{C}$, common to all sampled water pools and quite stable in time. This range, in fact, corresponds closely with that calculated by Chiodini et al. [1996] and confirms the long-term stability of the Salinelle geothermal system. However, this triangular diagram should be used with great caution when water samples are not in full equilibrium and if samples are not taken from deep well discharges [Giggenbach, 1988]. Furthermore, samples falling in the "partial equilibrated waters" area along isotherms defined by the Na-K geothermometer likely indicate mixing of a full-equilibrated geothermal water with a solution with low ionic strength and hence a dilution process [Romano and Liotta, 2020]. For the above reasons, the temperature values estimated in our case are indicative of the real temperature at depth, but they strongly suggest existence of anomalous high temperature conditions (> $100^{\circ} \mathrm{C}$ ) in the geothermal reservoir that feeds the Salinelle activity. 


\section{Jessica Maria Chicco et al.}

In order to evaluate both the temperature and the $\mathrm{pCO}_{2}$ of the geothermal fluids at depth, we used the $\log (\mathrm{Na} / \mathrm{K})$ vs. $\log \left(\mathrm{HCO}_{3}\right)$ diagram. Both temperature and $\mathrm{pCO}_{2}$ geoindicators are based on the $\mathrm{Na} / \mathrm{K}$ ratio and the total content of $\mathrm{HCO}_{3}{ }^{-}$, following the computations in Chiodini et al. [1991]. The temperature values are in the range of about $100-120^{\circ} \mathrm{C}$, thus slightly lower than the range indicated from the triangular Na-K-Mg plot of Figure 6 . The range of $\mathrm{pCO}_{2}$ values indicated in this plot is much higher than that calculated in the typical groundwater of Mt. Etna volcano [Allard et al., 1997; Giammanco et al., 1998; Brusca et al., 2001; Aiuppa et al., 2002, 2004]. The association observed in Figure 7 between high concentrations of calculated dissolved $\mathrm{CO}_{2}$ and high calculated temperatures in our samples, therefore, further supports the origin of the local fluids from condensation of high-enthalpy gases, originally released from magma, into the Salinelle hydrothermal system. It is worthy of note that the confining pressure values estimated from our samples are significantly lower than those found by Chiodini et al. [1996] for the same types of water. This condition highlights low-pressure conditions at depth within the hydrothermal reservoir underneath the Salinelle at the time of our sampling, and it justifies the observed low activity at the emissive pools during both the November 2018 and the February 2019 surveys.

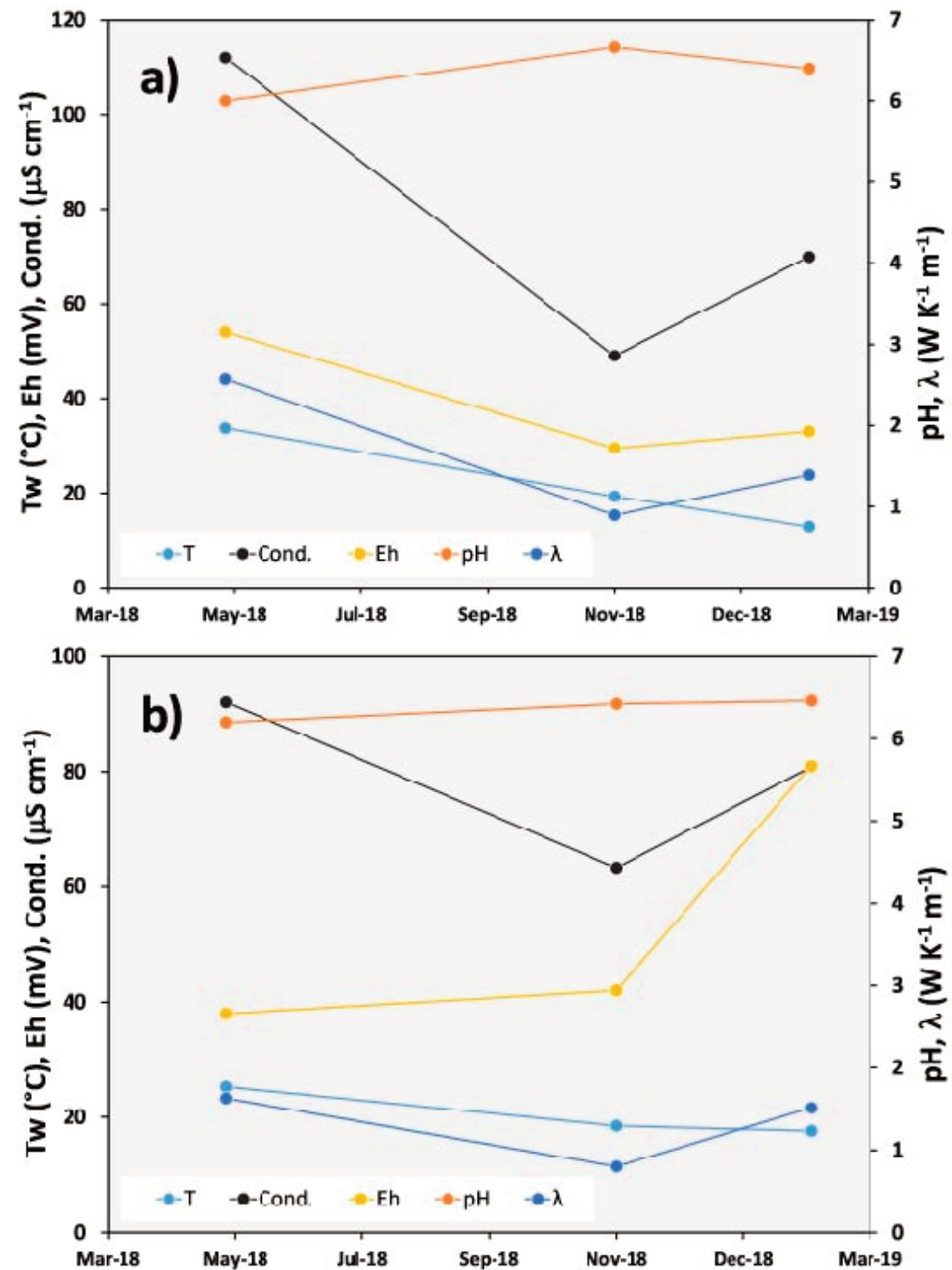

Figure 5. Temporal variations of the main physico-chemical parameters measured at a) SC3 and b) SC4 pools during the three field surveys of May 2018, November 2018 and February 2019. 


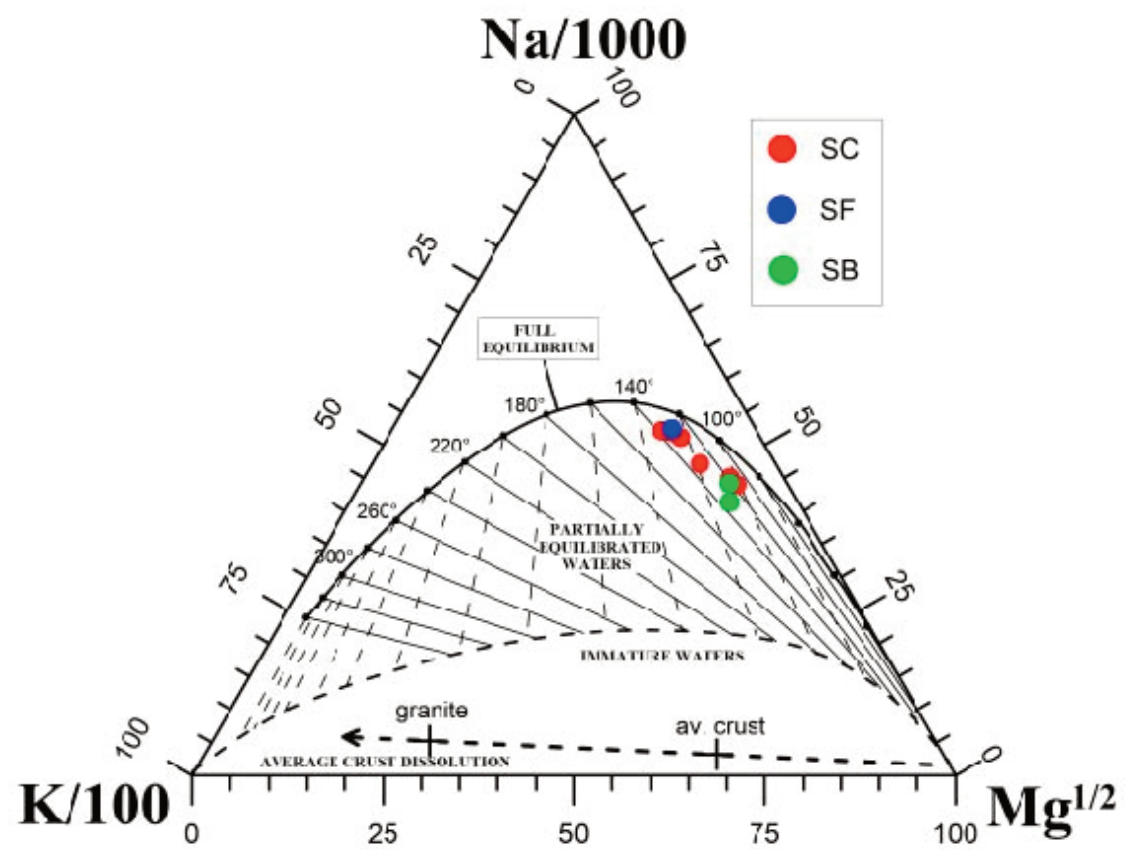

Figure 6. Triangular Na-K-Mg plot, modified from Giggenbach [1988], used for the geothermometric evaluation of water samples. SC = Salinelle dei Cappuccini; SF = Salinelle del Fiume; SB = Salinelle di San Biagio. All samples fall within the partially equilibrated waters, very close to the full equilibrium curve, along isotherms between 100 and $140^{\circ} \mathrm{C}$.

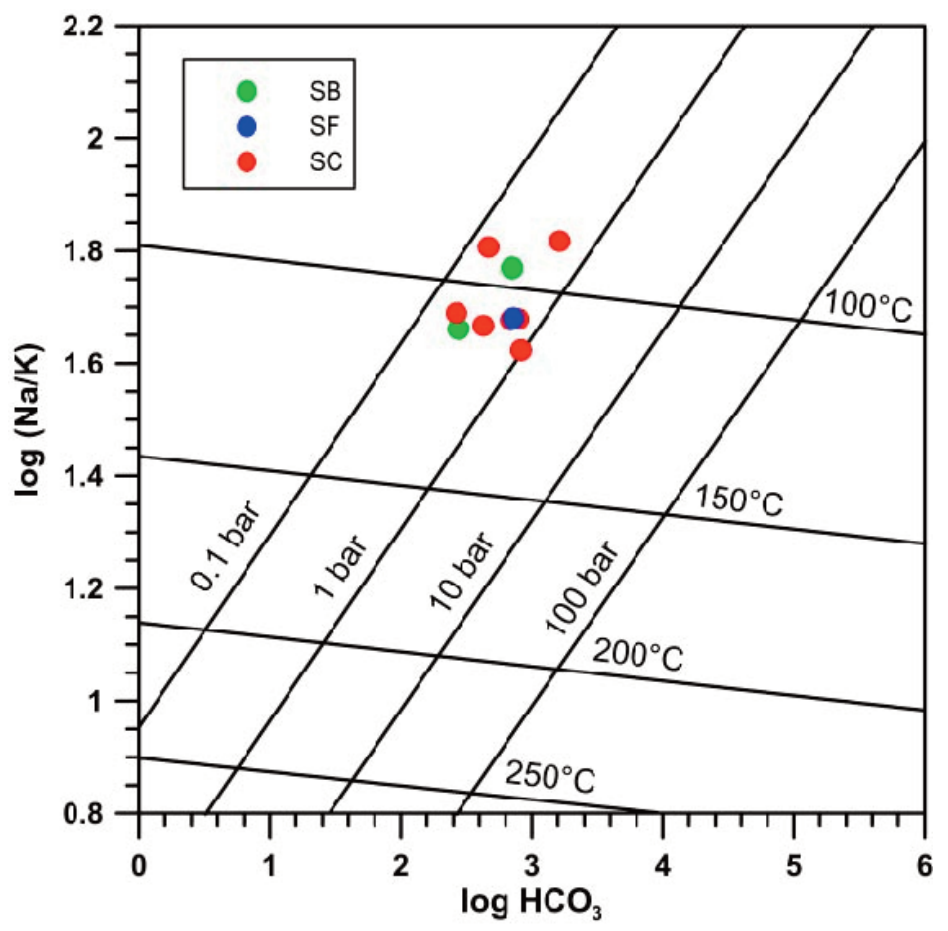

Figure 7. Plot of $\log (\mathrm{Na} / \mathrm{K})$ vs. $\log \left(\mathrm{HCO}_{3}^{-}\right)$, with temperature- $\mathrm{PCO}_{2}$ grid. Geoindicators are based on the computations from Chiodini et al. [1991]. All concentrations are in $\mathrm{mg} / \mathrm{L}$ and the salinity is assumed to result from a sum of equivalents of major ionic solutes of 2.4. SC = Salinelle dei Cappuccini; SF = Salinelle del Fiume; SB = Salinelle di San Biagio. 


\section{Jessica Maria Chicco et al.}

\subsection{Continuous temperature monitoring and correlation with geodynamics}

Muddy pools SC3 and SC4 were chosen for the continuous monitoring of water temperature, mostly because of their easy access and stability in time, as observed in recent years [Federico et al., 2019]. Temperature of water (fluid mud) was measured every 15 minutes from May 2018 to February 2019. During this period, some data were lost due to technical problems and to vandalism of the instrument.

The first problem was to "clean" our data from any environmental "noise" (Figure 8). Actually, from the plot in Figure 8 it is evident that water temperature at the SC3 pool was high during summer, whereas cold during winter. Also, most of the sudden short-term decreases observed in water temperature during the whole period of study seemed correlated with rainfall events, no matter how intense, thus suggesting an influence of rainfall, although minor and temporary, in lowering the temperature of water in the mud pools.

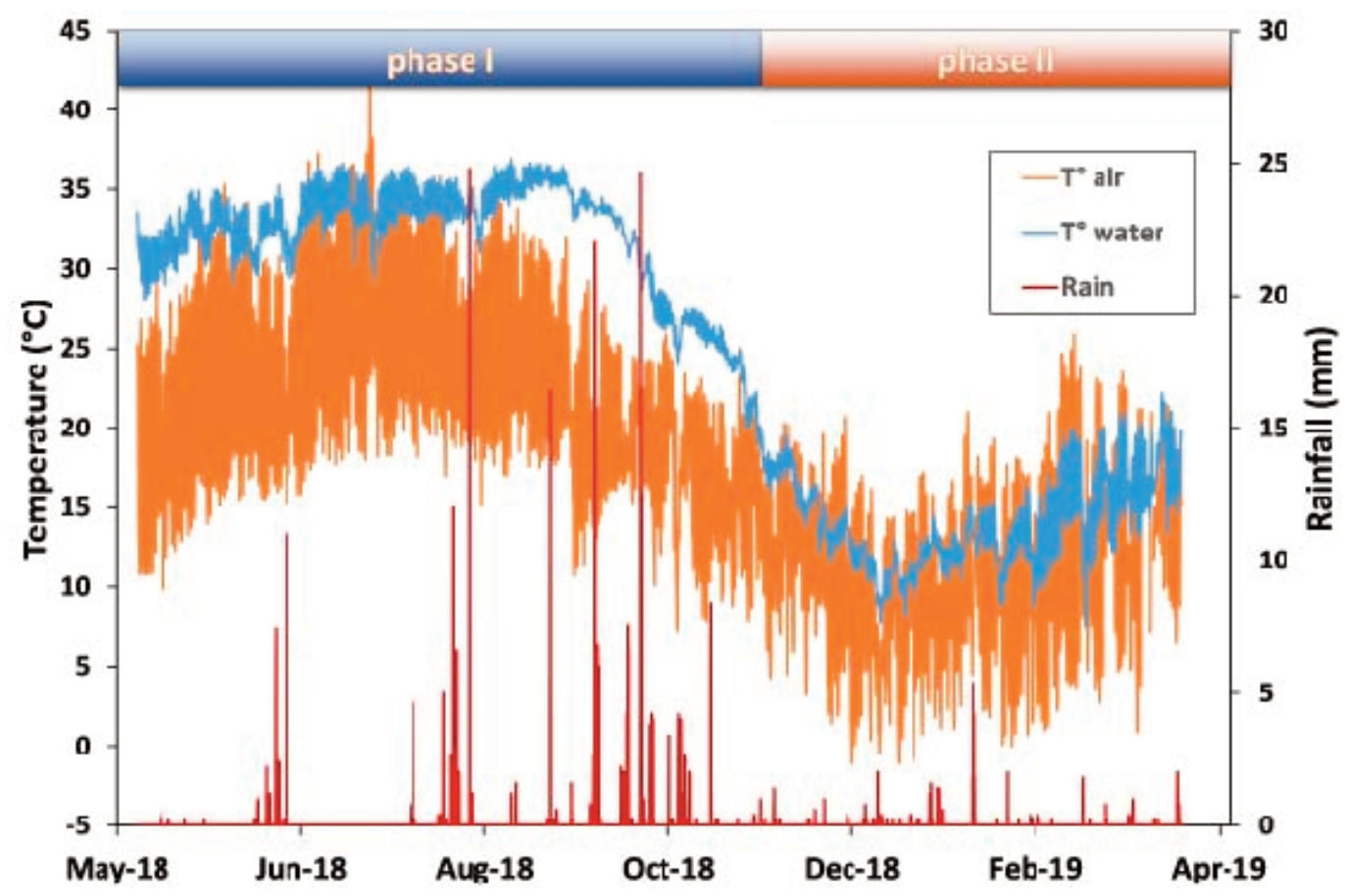

Figure 8. Temporal pattern of the hourly averages of water temperature (blue line), recorded at SC3 muddy pool from 7 May 2018 to 13 April 2019, compared to hourly averages air temperature (orange line) and rainfall (red bars) recorded at the SIAS Paternò meteorological stations. Colour boxes on top of plot indicate the two phases of activity observed during the monitored period (see text for details).

Therefore, a time-series analysis of raw water temperature data collected in the pools and of the air temperature and rainfall data from the Paternò weather station of the regional network managed by the Regional Department of Agriculture of Sicily (Servizio Informativo Agrometeorologico Siciliano) was performed, after converting all of the time series into hourly data. In particular, spectral analysis was performed using Fast Fourier Analysis of the time sequences of data. It permitted us to discriminate between temperature changes due to environmental effects from those due to volcanic/tectonic ones. In fact, while environmental changes clearly follow atmospheric conditions, "geology-induced" changes show cyclic variations with long periods (i.e., multi-month or longer) or they should have no periodicity at all.

The spectrograms for both air and water temperature time series (Figure 9) show similar patterns, with many frequency peaks related to cyclic changes due to day-night temperature variations (periods of 24 hours or less, the latter being "higher harmonics" of the basic $24 \mathrm{hr}$ cycle) as well as variations with longer period (a week, about a fortnight, about a month or more, although with a markedly lower amplitude than the daily period). The water temperature spectrogram (Figure $9 \mathrm{~b}$ ) clearly shows an influence mostly from the air temperature variations, as 
indicated by the same high-frequency peaks (periods of 24 hours and shorter) as those found in the air temperature signal (Figure 9a). However, this influence is seemingly not so strong, as suggested by the much smaller amplitude of all frequency peaks in the spectrogram of Figure $9 b$ and by the absence of the weekly cycle. Rainfall seems to affect water temperature in terms of production of 14 - 15 day cycles. The quasi-monthly period in water temperature seems to be uncorrelated both with air temperature and with rainfall, thus being possibly due to other environmental causes (e.g., tidal effects from lunar attraction). Therefore, water temperature is clearly affected by some environmental parameters, but this influence seems not so marked, thus suggesting a somewhat independent temporal behavior - mostly in the longer periods - that makes this parameter less sensitive to the main environmental variations.
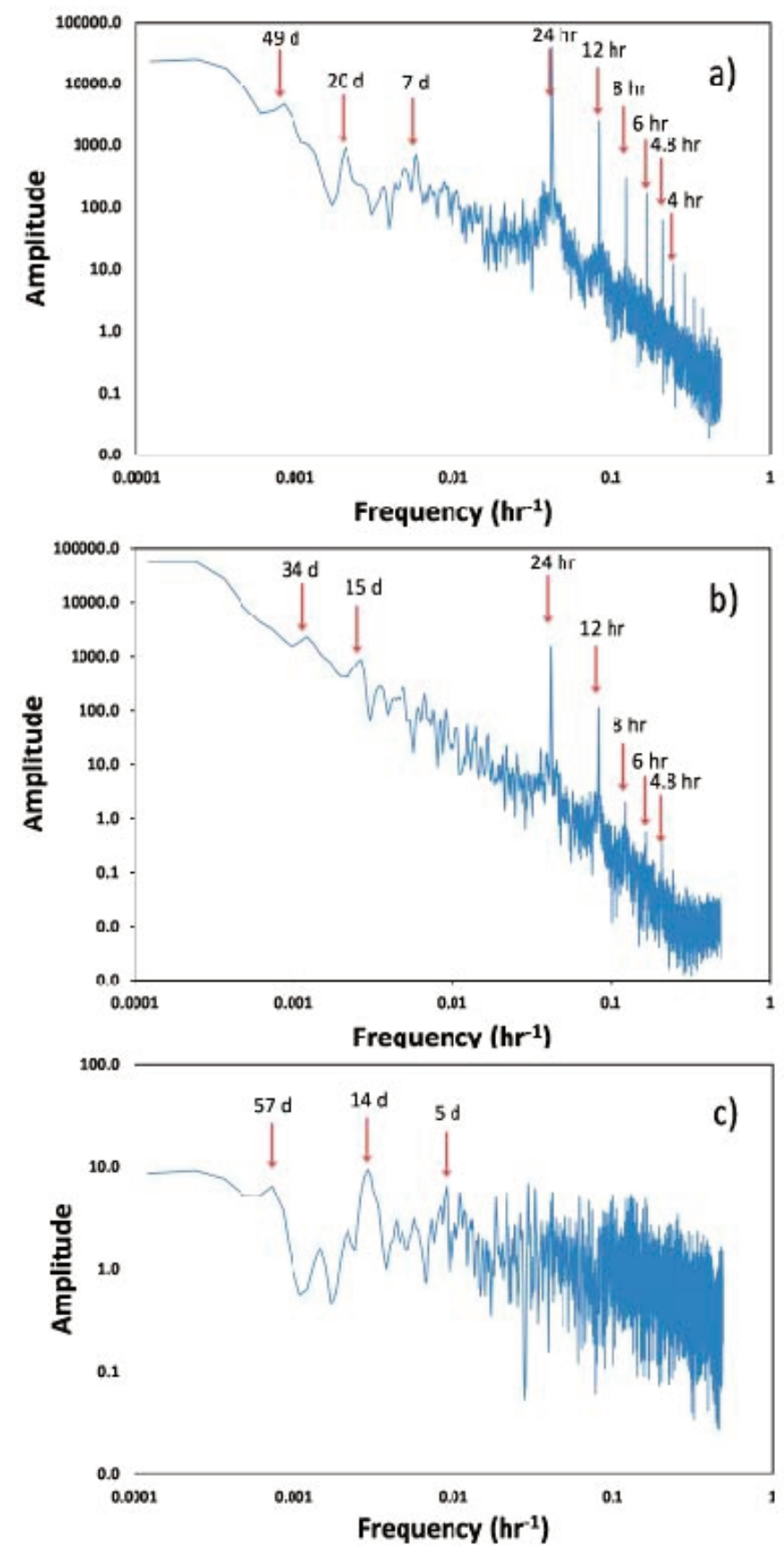

Figure 9. Spectrograms of frequencies in the time series of a) air temperature, b) water temperature and c) Rainfall continuously measured at the SC3 site of the Salinelle dei Cappuccini. Peaks in the plots highlighted with arrows show significant cyclic variations in the time series, whose period (in hours or days) is indicated above the arrows. 


\section{Jessica Maria Chicco et al.}

In order to have an idea on the possible causes of the discrepancies between water temperature and environmental parameters as obtained from spectral analysis, we studied in detail the time pattern of the above parameters in order to confront them (Figure 8). From a general point of view, it is clear that during the first period of monitoring (more or less until November 2018) water temperature in the SC3 pool was always higher than air temperature. Conversely, after November 2018 water temperature seems to follow air temperature, and both parameters show similar trends.

More in detail, the temporal pattern of the water temperature data from pool SC3 shows that during the period between May and early October 2018 temperature increased steadily, following an almost linear trend, until reaching about $35^{\circ} \mathrm{C}$ (that is, on average, an increase of $5^{\circ} \mathrm{C}$ in four months). Then a general rapid and strong decrease occurred, with values falling as low as $8^{\circ} \mathrm{C}$ in January 2019. Since early 2019, water temperature again slightly increased, following a similar rate as that observed from May to September 2018, until the end of the monitoring period.

We, therefore, divided the temperature signals (water and air) into two different subsets, with time threshold set on 22 November 2018 (see top boxes in Figure 8), and we calculated the correlation coefficients between water T and air $\mathrm{T}$ for each sub-period separately. From 7 May to 22 November the correlation was poor $\left(R^{2}=0.097\right)$, whereas in the following period it was significant $\left(\mathrm{R}^{2}=0.680\right)$. This suggests that before 22 November 2018 water temperature in pool SC3 was mainly controlled by a deep source of heat. This source caused the increasing trend of water temperature until 25 September 2018, when it started decreasing. From 25 September until the end of November the underground contribution becomes less predominant. This effect could be mainly ascribed to the greater amount of rain that fell over the area from August until early November, thus increasing the amount of shallow and cold groundwater that entered the feeder system of the Salinelle mud volcanoes and mixed with the local hydrothermal fluids. However, this seems in contrast with previous hydrogeochemical studies that modeled the Salinelle hydrogeological system as being totally independent of both Mt. Etna groundwater circulation and of rainwater recharge on the volcano [Chiodini et al., 1996; Aiuppa et al., 2000, 2004; Liotta et al., 2017]. The temporal variations of the physical-chemical parameters measured at SC3 and SC4 from May 2018 to February 2019 (Tables 1 to 3) shows markedly lower values both of electrolytic and thermal conductivity just in the November 2018 survey, which supports the hypothesis of dilution of local fluids from shallow low-salinity groundwater. However, the lack of chemical analyses of the Salinelle fluids during the May 2018 survey does not allow for a clear definition of the geochemical processes observed.

Water temperature data were also confronted with seismic and volcanic parameters recorded in the Etnean area during the same period of our monitoring (Figure 10). Due to the large temperature difference within a day, caused by variations of the local meteorological conditions as above described, we decided to use only the temperature values measured at 5:00 am as early morning is the best period to analyse in order to achieve the "real" temperature. We selected all seismic events (1020 in total) occurred during the study period and calculated the daily seismic energy release (Figure 10).

Figure 10 shows two very high peaks of seismic energy release: on 6 October 2018 (1.5E+09 Erg), on occasion of $\mathrm{a} \mathrm{M}=4.6$ earthquake, and on 26 December $2018(2.5 \mathrm{E}+09 \mathrm{Erg})$, on occasion of a $\mathrm{M}=4.9$ earthquake occurred during a violent seismic swarm that accompanied the onset of the 24-27 December 2018 flank eruption [Calvari et al., 2020]. It is worthy of note that the former earthquake occurred a few days after the turning point in water temperature increase at SC3. The strong $\mathrm{M}=4.6$ earthquake of 6 October 2018 was located only $6 \mathrm{~km} \mathrm{NW}$ of the Salinelle dei Cappuccini site, at a depth of $4 \mathrm{~km}$ (http://cnt.rm.ingv.it/en/event/20845861). Conversely, the stronger earthquake of 26 December 2018 as well as the epicenters of the many seismic events that occurred during the crisis that started on 24 December and ended in February 2019 were located much farther away and in a completely different sector of the volcano, that is on its upper and middle SE and NE slopes [Civico et al., 2019; De Novellis et al., 2019; Giampiccolo et al., 2020]. Also, the 24-27 December seismic energy release was associated with the onset and development of a three-day-long flank eruption of Mt. Etna that occurred at high altitude on the SE slopes of the volcano [Bonforte et al., 2019; De Novellis et al., 2019; Calvari et al., 2020], whereas the 6 October earthquake and the following smaller seismic events that lasted until 7 October were interpreted as purely tectonic, though probably indirectly correlated with new magma intrusion at depth beneath the volcano (S. Alparone and A. Ursino, pers. comm.).

The major strain releases occurred in only two moments: the first is associated with the single seismic event of 6 October 2018, whereas the second is associated with the 24-27 December seismic swarms (Figure 10). As shown in Figure 10, volcanic activity showed increases just before or during all of the main clusters of earthquakes since mid-August 2018 (i.e., August-September 2018; mid-November 2018; from 24 to 27 December 2018, when the 
December flank eruption occurred; April 2019). No strong volcanic activity was associated with the 6 October 2018 earthquake, although the shock seemingly followed an increase in the overall intensity of volcanic events recorded in mid-September, thus supporting the hypothesis that this seismic event was not triggered, at least not directly, from magma motion inside the volcano.

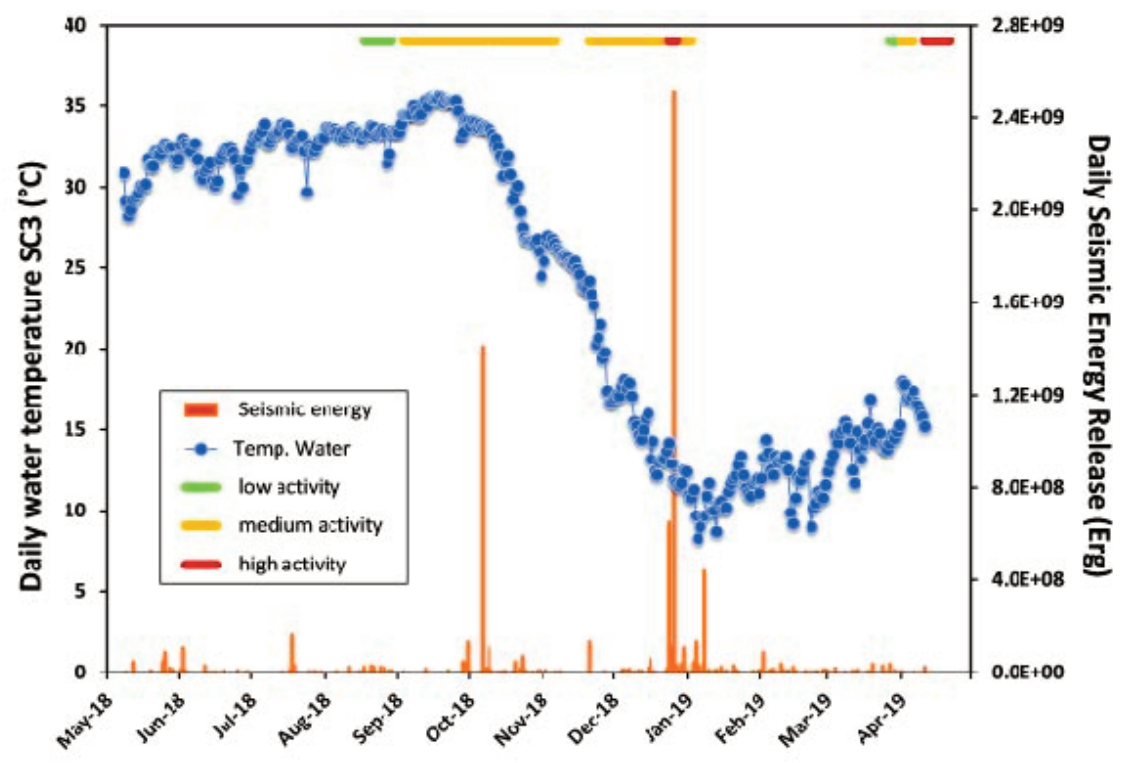

Figure 10. Total Daily Seismic Energy release (Erg) and daily values of water Temperature $\left({ }^{\circ} \mathrm{C}\right)$ recorded at 5:00 am at SC3 pool over the monitoring period (May 2018-April 2019). The first large seismic energy peak corresponds to the $\mathrm{M}=4.6$ earthquake of 6 October 2018, whereas the second and largest one corresponds to the seismic swarm accompanying the opening of the 24-27 December 2018 eruptive fissure. Volcanic activity during the period is shown on top of graph: green lines indicate low-intensity activity (summit ash explosions to mild intra-crater strombolian explosions); yellow lines indicate medium-intensity activity (intra-crater strombolian to strong strombolian); purple lines indicate high-intensity volcanic activity (summit or flank eruptions). Seismic data retrieved from http://sismoweb.ct.ingv.it/); volcanological data from Corsaro et al. [2017], Marchese et al. [2018] and from INGV weekly reports (http://www.ct.ingv.it/en/rapporti/multidisciplinari.html).

A tentative explanation for the observed variation in water temperature is based on two possible models, or a combination of both. The first model addresses a purely tectonic effect consisting of the increase in tectonic stress in the lower SW flank of Mt. Etna before the strong M = 4.6 earthquake of 6 October 2018, which likely induced large variations in crustal permeability in this sector of the volcano. The 6 October 2018 earthquake was actually among the strongest recorded on Mt. Etna in the last decades, and the strain release associated with it was remarkable (Figure 10), thus justifying possible strong changes in permeability both before and after the shock. We assume that hydrothermal fluids feeding the Salinelle mud volcanoes were affected by permeability changes in terms of increase in the fluid pressure inside the geothermal reservoir and hence in the flux of hot fluids released at the surface. This model would explain the initial steady increasing trend in water temperature until early October 2018. The following decrease in water temperature could be explained in terms of a large-scale permeability decrease, probably due to micro-cracking of crustal rocks preceding the main rupture event [Yamashita, 1999].

The second model takes into account the primary role of magma motion inside the volcano and links together all of the observed phenomena, in a cause-effect relationship. Similar to the previous model, we assume that the increase in water temperature at the surface vents from May to early October 2018 was the result of a greater heat flux due to fluid pressure increase in the Salinelle hydrothermal reservoir. However, in this case, a higher fluid pressure was caused by a greater input (and hence flux) of high-enthalpy magmatic fluids released from new 


\section{Jessica Maria Chicco et al.}

magma that was accumulating at depth beneath Mt. Etna and that eventually produced the 24-27 December flank eruption [Calvari et al., 2020]. Once the stored magma batch moved upward massively to start the eruptive process, a pressure drop occurred in the deepest portions of Etna's feeder system due to emptying of the deep magma chamber [Bonforte et al., 2019; Calvari et al., 2020]. Consequently, leakage of magmatic fluids through the deepest and most peripheral faults decreased dramatically in favor of their release through shallower faults and through the main conduits of the volcano. This mechanism is typical of fast ascent of gas-rich magma along the main conduits of Mt. Etna, as already observed and modeled several times in the past [Giammanco et al., 1995, 2013; Bruno et al., 2001; Caltabiano et al., 2004], and it would explain the rapid decrease in water temperature recorded at SC3 after October 1 15t 2018. In this context and in tectonic terms, the 6 October 2018 earthquake would be the early fragile response of the SW flank of the volcano to the massive and rapid intrusion of new magma into shallow portions of the volcanic system, which triggered the 24-27 December flank eruption, as testified by ground deformation [Bonforte et al., 2019]. Water temperature at the SC3 pool did not return to previous high levels because no new magma arrived and accumulated at depth until April 2019, and deep heat fluxes towards the Salinelle geothermal system dropped to background levels. Because the contribution of the deep geothermal source of heat became negligible, since late November 2018 water temperature at SC3 pool became influenced almost exclusively from air temperature variations.

\section{Concluding remarks}

Interactions between magmatic fluids and the shallow aquifers in the Southwestern flank of Mt. Etna volcano (Paternò and Belpasso, localities) were already discussed and modeled by some authors in the past [Aiuppa et al., 2000, 2002, 2004; Amici et al., 2013; Giammanco et al., 2016].

The great morphological variability as well as the more intense hydrothermal activity makes "Salinelle dei Capuccini” at Paternò the most interesting site to be studied. This was confirmed also from thermal and electrical field measurements, showing the highest values over the whole monitoring period. In particular, a good agreement between InfraRed thermal data and thermal field measurements was found, whereas thermal conductivity did not show any correlation with water temperature.

The chemical composition of muddy waters from the Salinelle allowed estimating the range of temperature at final chemical equilibrium in the geothermal reservoir that provides hypersaline fluids to the Salinelle mud vents. For all of the Salinelle sites, equilibrium temperature values ranged from about 100 to about $140^{\circ} \mathrm{C}$, generally consistent with previous estimates [Chiodini et al., 1996]. The calculated $\mathrm{pCO}_{2}$ values at equilibrium were found in the range 0.1 to 1.0 bar, which is 3 to 10 times lower than previous estimates [Chiodini et al., 1996]. It must be considered, however, that all calculations were carried out on water samples collected after the strong decrease in temperature of late September 2018, thus supposedly when the deep input of high-enthalpy and high-p $\mathrm{pO}_{2}$ fluids was very low.

Finally, water temperature continuously measured in the warmest pools at the most active site ("Salinelle dei Cappuccini”) revealed two distinct behaviors: a steady increasing trend of values until the end of September 2018, followed by a strong decrease right after the $M=4.6$ earthquake of October 6, 2018. Since 22 November 2018, water temperature closely followed air temperature variations. The convergence between water and air temperature trends suggests absence of anomalous deep input of high-enthalpy fluids to the geothermal system of the Salinelle and hence a stronger control from atmospheric parameters. The decreasing trend stopped after the very strong seismic sequence (Mmax $=4.9$ ) and the volcanic eruption of December 24-27, 2018. This large variation could be linked to strong variations in crustal permeability due to the earthquakes that may have changed the pathways of gas/water ascent into the mud volcanoes. Such processes may have been combined also with strong decreases in the magmatic gas flux at depth below Mt. Etna, known to be related to early stages of magma migration towards the surface [Giammanco et al., 1995, Caracausi et al., 2003].

Ascent of new gas rich magma from the deepest magma reservoir of Mt. Etna produces crustal fracturing along its path. Variations (both increasing and decreasing) in the flux of high-enthalpy fluids due to crustal stress changes induced by intrusion of newly ascending magma can modify the gas-water interaction process in the shallow aquifers crossed by major faults that act as gas escape pathways through the crust beneath Mt Etna. This can explain the marked modifications of the geochemical characteristics of the fluids issuing at the surface, mostly their temperature, in the mud pools of the Salinelle. 
Our study underscores the importance of monitoring both the geochemical and the physical parameters of the fluids emitted at the Salinelle mud vents as a potential new tool for volcano monitoring at Mt. Etna.

\section{Data and sharing resources}

- Meteorological data from the Paternò station, kindly provided from the Regional Department of Agriculture of Sicily (Servizio Informativo Agrometeorologico Siciliano)

- INGV weekly Bulletin covering seismic and volcanic activity of Mt. Etna, from May 2018 and May 2019 (http:/www.ct.ingv.it/index.php/monitoraggio-e-sorveglianza/prodotti-del-monitoraggio/bollettini-settimanalimultidisciplinari).

Acknowledgments. We wish to thank L. Olocco for his help during the field and the analytical work, which was part of his master thesis. We also thank the Paternò municipality for letting us enter the Salinelle dei Cappuccini area and the owners of the private lands where the Salinelle del Fiume and the Salinelle di San Biagio are located for giving us the permission to enter their properties. We acknowledge the Regional Department of Agriculture of Sicily (Servizio Informativo Agrometeorologico Siciliano) for kindly providing the meteorological data from the Paternò station. We thank N. Lautze and D. Rouwet for their useful comments and suggestions that helped improving this manuscript. This work was in part financed from the Italian project "Atlante Geotermico del Mezzogiorno" (http://atlante.igg.cnr.it) funded by the Italian Council for Research.

\section{REFERENCES}

Aiuppa, A., P. Allard, W. D’Alessandro, A. Michel, F. Parello, M. Treuil and M. Valenza (2000). Mobility and fluxes of major, minor and trace metals during basalt weathering and groundwater transport at Mt. Etna volcano (Sicily), Geochim. Cosmochim. Acta, 64, 1827-1841.

Aiuppa, A., L. Brusca, W. D’Alessandro, S. Giammanco and F. Parello (2002). A case study of gas-water-rock interaction in a volcanic aquifer: the south-western flank of Mt.Etna (Sicily), In: Stober I., Bucher K. (Editors), Water-Rock Interaction. Kluwer Academic Publishers, Netherlands, 125-145.

Aiuppa, A, P. Allard, W. D’ Alessandro, S. Giammanco, F. Parello and M. Valenza (2004). Magmatic Gas Leakage at Mount Etna (Sicily, Italy): Relationships With the Volcano-Tectonic Structures, the Hydrogeological pattern and the Eruptive Activity, In: Geophysical Monograph series. Bonaccorso A., Calvari S., Coltelli M., Del Negro C., Falsaperla S. (Eds.). https://doi.org/10.10291/143GM09.

Amici, S. M. Turci, F. Giulietti, S. Giammanco, M. F. Buongiorno, A. La Spina and L. Spampinato (2013). Volcanic environments monitoring by drones mud volcano case study, International Archives of the Photogrammetry, Remote Sensing and Spatial Information Sciences, XL-1/W2, 2013, UAV-g2013, 4-6 September 2013, Rostock, Germany.

Bai, W., L.W. Kong and A. Guo (2013). Effects of physical properties on electrical conductivity of compacted lateritic soils, J. Rock Mech. Geotech. Engin., 5, 406-411. http://dx.doi.org/10.1016/j.jrmge.2013.07.003.

Bonforte, A., F. Guglielmino and G. Puglisi (2019). Large dyke intrusion and small eruption: The December 24, 2018 Mt. Etna eruption imaged by Sentinel-1 data. Terra Nova, 00, 1-8. http://dx.doi.org/10.1111/ter.12403

Bonini, M. (2009). Mud volcano eruptions and earthquakes in the Northern Apennines and Sicily, Italy, Tectonophysics, 474, 723-735. http://dx.doi.org/10.1016/j.tecto.2009.05.018

Bonini. M. (2012). Mud volcanoes: Indicators of stress orientation and tectonic controls. Earth-Sci. Rev., 115(3), $121-152$.

Calvari, S., G. Bilotta, A. Bonaccorso, T. Caltabiano, A. Cappello, C. Corradino, C. Del Negro, G. Ganci, M. Neri, E. Pecora, G. G. Salerno and L. Spampinato (2020). The VEI 2 Christmas 2018 Etna Eruption: A small but intense eruptive event or the starting phase of a larger one?, Remote Sens., 12, 905; http://dx.doi.org/10.3390/rs12060905.

Castaldini, D. and P. Coratza (2017). Mud Volcanoes in the Emilia-Romagna Apennines: Small Landforms of 


\section{Jessica Maria Chicco et al.}

Outstanding Scientific Value. In: M. Soldati and M. Marchetti (eds.). Landscapes and Landforms of Italy. World Geomorphological Landscapes, 19. http://dx.doi.org/10.1007/978-3-319-26194-2_19

Chicco J.M., N. Giordano and G. Mandrone (2018). The use of open-source electronic platforms to monitor the efficiency of Borehole Thermal Energy Storage Systems (BTES) in porous materials by means of lab scale modelling, Rend. Online Soc. Geol. It., 46, 155-160, https://doi.org/10.3301/ROL.2018.67.

Chicco J.M., D. Vacha and G. Mandrone (2019). Thermo-Physical and Geo-Mechanical characterization of faulted carbonate rock masses (Valdieri, Italy), Remote Sens., 11, 179. http://dx.doi.org/10.3390/rs11020179.

Chiodini, G., W. D’Alessandro and F. Parello, (1996). Geochemistry of gases and waters discharged by the mud volcano at Paternò, Mt. Etna (Italy), Bull. Volcanol., 58, 51-58.

Civico R., S. Pucci, R. Nappi, R. Azzaro, F. Villani, D. Pantosti, F. R. Cinti, L. Pizzimenti, S. Branca, C. A. Brunori, M. Caciagli, M. Cantarero, L. Cucci, S. D’Amico, E. De Beni, P. M. De Martini, M. T. Mariucci, P. Montone, R. Nave, T. Ricci, V. Sapia, A. Smedile, G. Tarabusi, R. Vallone and Venuti A. (2019) Surface ruptures following the 26 December 2018, Mw 4.9, Mt. Etna earthquake, Sicily (Italy), J. Maps, 15:2, 831-837, http://dx.doi.org/10.1080/17445647.2019.1683476

Davies, R., M. Brumm, M. Manga, R. Rubiandini, R. Swarbrick and M. Tingay (2008). The East Java mud volcano (2006 to present): An earthquake or drilling trigger?, Earth Planet. Sci. Lett., 272, 627-638.

De Novellis, V., S. Atzori, C. De Luca, M. Manzo, E. Valerio and M. Bonano (2019). DInSAR analysis and analytical modeling of Mount Etna displacements: The December 2018 volcano-tectonic crisis, Geophys. Res. Lett., 46, https://doi.org/10.1029/2019GL082467

Deville E. (2009). Mud Volcano Systems. In: Volcanoes: Formation. Eruptions and Modelling. N. Lewis. A. Moretti (Eds.), 5, 95-126 ISBN 978-1-60692-916-2. Nova Science Publishers, Inc.

Federico, C., M. Liuzzo, G. Giudice, G. Capasso, A. Pisciotta and M. Pedone (2019). Variations in $\mathrm{CO}_{2}$ emissions at a mud volcano at the southern base of Mt Etna: are they due to volcanic activity interference or a geyser-like mechanism?, Bull. Volcanol., 81:1, https://doi.org/10.1007/s00445-018-1261-x.

Giammanco S., S. Gurrieri and M. Valenza (1995). Soil $\mathrm{CO}_{2}$ degassing on Mt. Etna (Sicily) during the period 19891993: discrimination between climatic and volcanic influences, Bull. Volcanol., 57, 52-60.

Giammanco S., S. Carbone and A. Pistorio (2016). Il geosito "Sistema delle Salinelle del Monte Etna" (Paternò e Belpasso - Sicilia Orientale). Geologia dell’Ambiente, Suppl. 3/2016. ISNN 1591-5352

Giampiccolo, E., O. Cocina, P. De Gori and C. Chiarabba (2020). Dyke intrusion and stress-induced collapse of volcano flanks: The example of the 2018 event at Mt. Etna (Sicily, Italy), Scientific Reports, 10, 6373, https://doi.org/10.1038/s41598-020-63371-3

Giggenbach, W.F. (1988). Geothermal solute equilibria. Derivation of Na-K-Mg-Ca geoindicators, Geochim. Cosmochim. Acta, 52 (12), 2749-2765. https://doi.org/10.1016/0016-7037(88)90143-3.

Giordano N., J. Chicco, G. Mandrone, M. Verdoya M. and Wheeler W.H. (2019). Comparing transient and steady-state methods for the thermal conductivity characterization of a borehole heat exchanger field in Bergen, Norway. Environ. Earth Sci., 78, 460. https://doi.org/10.1007/s12665-019-8397-7.

Kilburn C. R. (2018). Forecasting Volcanic Eruptions: Beyond the Failure Forecast Method, Front. Earth Sci., 6, 133. http://dx.doi.org/10.3389/feart.2018.00133

Liotta, M., W. D’Alessandro, A. Arienzo and M. Longo (2017). Tracing the circulation of groundwater in volcanic systems using the 87SR/86Sr ratio: Application to Mt. Etna, J. Volcanol. Geotherm. Res. 331, 102-107.

Manga M., M. Brumm, M. L. Rudolph (2009). Earthquake triggering of mud volcanoes, Mar. Petrol. Geol., 26, 17851798. http://dx.doi.org/10.1016/j.marpetgeo.2009.01.019.

Napoli R., G. Currenti, S. Giammanco, F. Greco, S. Maucourant (2020). Imaging the Salinelle Mud Volcanoes (Sicily, Italy) using integrated geophysical and geochemical surveys, Ann. Geophys., 63, PE442, http://dx.doi.org/10.4401/ag-8215.

Panzera F., S. Sicali, G. Lombardo, S. Imposa, S. Greta and S. D’Amico (2016). A microtremor survey to define the subsoil structure in a mud volcanoes area: the case study of Salinelle (Mt. Etna. Italy), Environ. Earth Sci., 75, 1140.

Pralle N., M. Kulzer and G. Gudehus (2003). Experimental evidence on the role of gas in sediment liquefaction and mud volcanism. In: Geological Society London Special Publications (P. Van Rensbergen. R.R. Hillis. A.J. Maltman and C.K. Morley. Eds.), 216, 159-171, http://dx.doi.org/10.1144/GSL.SP.2003.216.01.11

Romano, P. and M. Liotta, (2020). Using and abusing Giggenbach ternary Na-K-Mg diagram, Chem. Geol., 541, 119577. https://doi.org/10.1016/j.chemgeo.2020.119577 
Wan Z., Y. Yao, K. Chen, S. Zhong, B. Xia and Y. Sun (2019). Characterization of mud volcanoes in the northern Zhongiiannan Basin, western South China Sea, Geol. J., Wiley, 54:177-188. http://dx.doi.org/10. 1002/gi.3168. Yamashita, T. (1999). Pore Creation due to Fault Slip in a Fluid-permeated Fault Zone and its Effect on Seismicity: Generation Mechanism of Earthquake Swarm, Pure Appl. Geophys. 155, 625-647. 